\title{
SETTING THE “RIGHT” GOAL: POST M\&A INNOVATION PERFORMANCE AND GOAL ORIENTATION
}

\author{
Trang Thu DOAN (1D* \\ International School, Vietnam National University Hanoi, Vietnam \\ Received 10 February 2020; accepted 8 June 2020
}

\begin{abstract}
Pharmaceutical firms spend billions of dollars to develop the next breakthrough drug and to maintain their market shares. We investigate how pharmaceutical firms use mergers and acquisitions to boost their innovation performance which has been found to result in better performance outcomes. Adding to the recent research on mergers and acquisitions, we found that firms that are explicit with their R\&D goal orientation from the beginning of the acquisition journey are more successful in their innovation endeavours than firms with other goal orientation. Further, the firms' prior acquisition experience appears to aid their innovation performance. However, we found that target size can affect the postacquisition innovation performance but has diminishing returns as target size increases. Ultimately, our findings suggest that having an explicit R\&D goal orientation is really important for a healthy innovation pipeline for pharmaceutical firms.
\end{abstract}

Keywords: mergers and acquisitions, innovation, R\&D, goal orientation, acquisition experience, organizational learning, pharmaceutical industry.

JEL Classification: L25, L65, O32.

\section{Introduction}

Mergers and acquisitions (henceforth referred to as M\&As) has been regarded as an important strategy for firms that want to enhance their innovation and obtain sustainable competitive advantage (Ahuja \& Katila, 2001; Cloodt et al., 2006; Hamel, 2000; Han et al., 2018). This strategy is particularly crucial in the pharmaceutical industry considering the fact that many pharmaceutical firms are facing the threats of upcoming patent expiry of blockbuster drugs, i.e. drugs that generate more than $\$ 1$ billion annually, and increasing costs of drug development (Fernald et al., 2017; Khanna, 2012; Malik, 2009). Prior research suggests that through M\&As, firms can acquire valuable resources such as important technologies or know-how from their partners to enhance their research and development $(\mathrm{R} \& \mathrm{D})$ and innovation performance (Ahuja \& Katila, 2001; Chaudhuri \& Tabrizi, 1999). Despite this expectation, findings from empirical research on the relationship between M\&As and innovation performance are inconclusive. While there is evidence that M\&As can enlarge firm innovative capabilities (Cassiman et al., 2005), some studies demonstrate that the long-run innovation growth and development of new products can be negatively affected as acquirers usually target firms that develop products with related technological skills and this eventually limits knowledge diversification (Comanor \& Scherer, 2013; Ornaghi, 2009).

A large number of studies on M\&As and innovation performance have argued that to obtain improvement in innovation performance, complementarity in the resources and capabilities of the acquirer and the target is a must (Kim \& Finkelstein, 2009; Larsson \& Finkelstein, 1999; Makri et al., 2010; Shelton, 1988). In addition, similarity and proximity between the two partners' resources are important contingencies (Baum et al., 2000; Chakrabarti \& Mitchell, 2013; Schildt \& Laamanen, 2006). In other words, if an acquirer can find a target that offers resources with sufficient similarities and complementarities, their post M\&A innovation performance is more likely to improve.

Does the acquirer find such a target by chance or by luck? Most likely not. We assume that the target selection process is greatly influenced by the acquirer's motive (as to why they want to engage in an acquisition), which, in turn, influence the innovation performance after the integration. An M\&A transaction can be initiated by various motives such as to gain market power, to

${ }^{*}$ Corresponding author. E-mail: trangdt@isvnu.vn 
expand their business geographically, to obtain efficiency, to share resources and so on (Ravenscraft \& Scherer, 1987; Trautwein, 1990). These motives can drive firms' behavior and decisions right from the target selection phase. An acquirer with an explicit R\&D motive may consider R\&D enhancement as priority and have a tendency to find a target from which they can obtain valuable capabilities and resources to improve their innovation performance (Schweizer, 2005). Interestingly, if the acquirer purposely sources for technology from the M\&A deal, the combined $R \& D$ intensity can increase after the integration even if the research areas of two partners are unrelated (Ruckman, 2009).

Despite of this importance of the role of M\&A motive in technological M\&As, little research has focused on investigating its influence on post M\&A innovation performance (for exceptions see Higgins \& Rodriguez (2006) and Ruckman (2009)). We suggest that having a clear R\&D motive from the beginning not only guides the acquirer in the target selection phase but can also facilitate knowledge transfer during the integration stage. This argument stems from the motivational theory (Dweck, 1986), attentionbased view (Ocasio, 1997; Yu et al., 2005) and the goalorientation theory (Button et al., 1996). Empirical findings from Hakanson (1995) demonstrate that the attention to include $\mathrm{R} \& \mathrm{D}$ units in the post M\&A integration process can affect the sharing, transfer and exploitation of technical resources and capabilities between firms. Therefore, we propose that an acquisition with an explicit R\&D motive is associated with greater post-acquisition innovation performance than an acquisition initiated with an alternative goal orientation.

Our setting is the pharmaceutical industry and following prior research, we measure post-acquisition innovation performance by the number of patents that are granted to a firm in two years after the M\&A integration (Ahuja \& Katila, 2001; Jeon et al., 2015; Ornaghi, 2009; Penner-Hahn \& Shaver, 2005). Regarding the motive of the acquisition, we extract this information based on the description of the goal of the acquisition as given in our data source - Zephyr - these deal descriptions are in turn collected from press releases and company reports.

In addition to the relationship between an $\mathrm{R} \& \mathrm{D}$ goal orientation and post M\&A innovation performance, we also explore two contingencies that may have an impact on this relationship. First, firms with strong acquisition capabilities, i.e., firms with many acquisition experiences, are more likely to pursue a broader range of targets with more valuable resources, and hence, provide better capabilities facilitating the knowledge transferring and absorbing during the integration process (Hayward, 2002; Prahalad \& Bettis, 1986). We suggest that acquirer's experience on prior M\&As both positively influences post M\&A innovation performance and positively moderates the relationship between having an R\&D goal orientation and innovation performance. Second, while a large deal in general indicates more capabilities to strengthen the firm
(Capron \& Pistre, 2002), it may pose significant integration challenges for the acquirer, particularly in terms of combining technological resources (Paruchuri et al., 2006; Puranam et al., 2006; Puranam \& Srikanth, 2007). Therefore, we propose two alternative hypotheses that deal size either positively or negatively relates to post M\&A innovation performance. In addition, considering its moderating effect on the relationship between having an R\&D goal orientation and post M\&A innovation performance, we anticipate that the effect can be either positive or negative.

With the above investigation, the contribution of this study is at least twofold. First, we extend the research stream on M\&A motive, target selection, and post-acquisition innovation performance by addressing the important role of having an $\mathrm{R} \& \mathrm{D}$ goal orientation right at the beginning of the procedure on determining innovation performance. Second, to unveil this relationship, we are the first to apply theories from psychology research in the context of one of the most popular diversification strategies - M\&As. We hope that our attempt will trigger more interest and efforts to connect different perspectives from other fields and apply them to address strategic management issues.

\section{Mergers and acquisitions and innovation performance}

\section{1. $M \& A$ motives, $R \& D$ goal orientation and innovation performance}

M\&As can be driven by a number of different motives. Some of the most notable motives of M\&As that are indicated in prior research include building economies of scale and scope, gaining efficiency, penetrating new markets, increasing market share, and diversification (Hagedoorn \& Sadowski, 1999; Trautwein, 1990). In addition, the dramatic rise of M\&As activity in high-technology sectors such as biotechnology or telecommunications in the 1990s are attributed to technological motives (Ahuja \& Katila, 2001; Chaudhuri \& Tabrizi, 1999). An M\&A deal with a technological motive implies that the acquiring firm has a desire to obtain know-how or technological assets of the target firms to enhance their innovation performance and gain sustainable competitive advantages (Ahuja \& Katila, 2001; Cloodt et al., 2006; Hamel, 2000). To many technology firms, M\&As is a crucial channel through which they can make significant improvement in their technical capabilities, and as a result, develop their products and enhance their market power (Agarwal \& Helfat, 2009; Eisenhardt \& Martin, 2000; Santos \& Eisenhardt, 2009). The acquisition of external technological sources becomes even more essential when managers are aware of the fact that innovation and many competitive advantages cannot be simply developed using their own internal resources (Ahuja \& Katila, 2001).

Regarding the motives of M\&As in pharmaceutical industry, prior research suggests that the motives behind these acquisitions were quite similar, which are the desire 
to fill up the $R \& D$ pipeline, gaining access to potential blockbusters in the short-term and acquiring know-how that would contribute to the acquirer's performance and growth strategy (Higgins \& Rodirguez, 2006). However, some other quantitative studies demonstrate that not all M\&As are driven by these motives, or, in other words, there are other motives which are not-so-related-to-technology behind pharmaceutical M\&As. For instance, in one out of the six M\&A cases investigated in Schweizer (2005), the goal of the deal was to get access to new customers, increase efficiency and enhance the position of the firm in the industry. In addition, while examining the deal rationale of the pharmaceutical M\&As in our sample of data, we notice various non-technological motives of the deal such as "to offer a unique portfolio of brands that produce some of the strongest consumer franchises around the world" as quoted by Bernd Beetz, CEO of Coty Inc. about the acquisition of DLI Holding LLC in 2007 (both US companies).

In sum, the above arguments and findings suggest that M\&As in the pharmaceutical industry can be driven by both technological and non-technological motives. This is consistent with Bower (2001) and Shrivastava (1986), suggesting that all M\&A strategies are not alike, therefore, knowledge of the strategic motives underlying them are important to understand the M\&A process and to implement different types of acquisitions. For acquirers who aim to enhance post M\&A innovation performance, understanding clearly their M\&A motives is even more important due to two main reasons. First, we assume that firm behavior and decisions are driven by their motives throughout the whole M\&A procedure, starting right from the target selection phase, where the acquisition success begins (Graebner et al., 2010). The "greatest combination potential" (Larsson \& Finkelstein, 1999) is likely to be achieved when there is a balance of similarities and complementarities in the resources and capabilities of the acquirer and the target (Graebner et al., 2010; Lange \& Wagner, 2019). Either too few or too many similarities and complementarities between the two firms can cause challenges to the process of transfer and combination of technologies and know-how (Ahuja \& Katila, 2001; Higgins \& Rodriguez, 2006). Explicitly stating a technology-related motive in advance will facilitate acquirers in searching for a target that offers potentials for technological combination. This was confirmed by findings from prior literature on technology sourcing acquisitions such as Chaudhuri and Tabrizi (1999), Higgins and Rodriguez (2006), Ruckman (2009), and Schweizer (2005). According to these studies, firms that acknowledge technology sourcing as their motives for acquisitions deliberately target technology capabilities possessed by other firms to supplement or substitute their internal R\&D.

Second, drawing arguments from the motivational theory (Dweck, 1986), attention based view (Ocasio, 1997; Yu et al., 2005) and the goal-orientation theory (Button et al., 1996), we anticipate that having R\&D goal orientation will guide the attention of firms to focus on technology related tasks during the integration process, which will improve post-acquisition innovation performance. The theory on goal orientation and the attention based view are applied widely in research on psychology and individual behaviors; however, many scholars have suggested that these theories hold great promise for application in organizational research (Bobko \& Colella, 1994; Farr et al., 1993). While prior research claims different types of goal orientation, we suggest that arguments on the learning goal orientation (in contrast to performance goal orientation) are most suitable to apply in our case. From a learning goal orientation, individuals attempt to understand something new or to increase their skills and competency in given activities (Button et al., 1996; Vandewalle et al., 2001). In an organization, a learning goal orientation may motivate employees to participate in training programs to acquire knowledge and skills relevant to their job setting (Button et al., 1996). Applying similar logics, we suppose that once an acquiring firm has an R\&D goal orientation, they will thrive in their search for resources and capabilities that can have an impact on their R\&D, and participate in technology-related tasks, even though challenging, during the integration process to achieve their goal (Button et al., 1996; Diener \& Dweck, 1978).

The acquisition of organizational resources, especially the technology-related resources is always a complex and delicate process that requires a significant commitment of managerial attention (Ahuja \& Katila, 2001; Haspeslagh \& Jemison, 1991). In some cases, managers from the acquiring firm can become so pre-occupied with negotiation and integration tasks that their attention is diverted from other activities such as internal R\&D (Hitt et al., 1996). Therefore, sufficient attention to technology-related tasks during the integration process is necessary for firms if they want to develop their innovation performance. This attention not only keeps managers focused on the R\&D goal but can also positively influence the process of sharing, transferring and exploring technological capabilities across firms in the transaction (Hakanson, 1995). Therefore, we propose:

H1: An acquisition with an explicit R\&D goal orientation is associated with greater post-acquisition innovation performance than an acquisition initiated with an alternative goal orientation.

\section{2. $M \& A$ experience, $R \& D$ goal orientation, and innovation performance}

In addition to an R\&D motive, acquisition capability, revealed through the accumulation of acquirer's experience on prior acquisitions (Kaul \& Wu, 2015), is suggested to be important for firms to gain innovation enhancement after the M\&A integration due to three major reasons.

First, firms with greater capabilities are more likely to pursue a broader range of targets and are also better in identifying and evaluating targets (Laamanen \& Keil, 2008). This promises high chances to find a superior target with many valuable resources that are fit with the acquirer's 
M\&A motives (Kaul \& Wu, 2015). In addition, when the two firms interact, conflicts and integration costs may occur. Knowledge from accumulated acquisition experience can help to manage and overcome these challenges (Hitt et al., 2001; Prahalad \& Bettis, 1986; Puranam \& Srikanth, 2007). Furthermore, the effectiveness and efficiency of capturing, absorbing, and integration of knowledge during the M\&A integration phase is facilitated through a learning mechanism which is generated through conducting many acquisition in the past (Hayward, 2002). In other words, prior experience can affect the flow of technological knowledge from the target to the acquiring firm (Jo et al., 2016; Lee et al., 2019).

In line with the above arguments, we anticipate that post-acquisition innovation performance can be influenced by acquisition capability, obtained through experience on prior M\&A deals. That is, firms with a lot of acquisition experience are more likely to gain an improvement in innovation after their integration with another firm. Also, the impact of an R\&D goal orientation is stronger when the acquirer has conducted many M\&A transactions beforehand. We hypothesize:

H2: M\&A experience is positively related to post-acquisition innovation performance.

Having prior M\&A experience not only equips the firms with better acquisition integration routines to improve their innovation performance, but we argue that such experience improves the innovation performance of the firms with an explicit R\&D goal orientation. As argued above, firms with an explicit R\&D goal orientation are focused on which processes to pay attention to and do not get deviated from other operational tasks that divert their attention (Hitt et al., 1996). Firms with prior M\&A experience have efficient routines which can help the managers to perform more efficiently in their day to day R\&D tasks. Therefore, we suggest that firm's M\&A experience moderates the relationship between an explicit R\&D goal orientation and post-acquisition performance such that firms with more M\&A experience have better innovation performance than firms with less M\&A experience. Thus, we hypothesize:

H3: M\&A experience positively moderates the relationship between R\&D goal orientation and post-acquisition innovation performance. That is, the relationship $R \& D$ goal orientation and post-acquisition innovation performance is stronger for firms with more M\&A experience (than for firms with less M\&A experience).

\subsection{Deal Size, R\&D goal orientation, and innovation performance}

According to the resource based view, one of the most popular reasons that firms pursue technology acquisitions is to gain competitive advantages through acquiring technologies, know-how or specific products which are possessed or developed by the other firm (Birkinshaw et al., 2000; Graebner, 2004; Ranft \& Lord, 2000). In addition, they can also benefit from capabilities embedded in the knowledge of employees from the target firm (Graebner et al., 2010). By combining their own resources with these external capabilities, the acquirers expect to create more value and enhance their long-term innovation as well as performance (Graebner, 2004; Schweizer, 2005).

As mentioned in previous sections, in order to achieve positive combination, similarities and complementarities in the resources of the two firms are necessary (Kim \& Finkelstein, 2009; Larsson \& Finkelstein, 1999; Makri et al., 2010; Shelton, 1988). In addition, the magnitude or size of the target is also important. As the purpose of the integration is to combine capabilities of the two firms, the acquirer should be able to capture at least some part of the resources that the target possesses (Capron \& Pistre, 2002). Hence, the larger the potential target, the greater resources it can offers and the more likely that the acquirer can find resources and capabilities that are compatible and valuable for them to acquire. In addition, larger target firms in general have greater $R \& D$ base and generate more patents, which can be helpful for the R\&D and innovation in the acquiring firm (Ahuja \& Katila, 2001). Therefore, deal size can have a positive impact on post-acquisition innovation performance.

However, a large amount of newly acquired knowledge may prove disruptive of existing organizational routines, resulting in a decrease in innovation performance. In addition, the acquisition of substantial resources will need to be managed carefully to maintain the valuable capabilities, which can pose significant costs and integration challenges for the acquirer (Paruchuri et al., 2006; Puranam et al., 2006; Puranam \& Srikanth, 2007). Furthermore, interaction and communication among members belonging to the two firms is required for efficient knowledge transfer (Shibayama et al., 2008). In the acquisition of a large deal, we suppose that it will take time for the employees from both firms to get acquainted to each other. Additionally, conflicts might occur during this integration process as individuals identify themselves as "us" versus "them" (Vaara et al., 2012). The larger the acquired firm is, the more time-consuming and troublesome this integration of knowledge may take.

Considering the above arguments, we propose two alternative hypotheses for the direct effect of deal size on post M\&A innovation performance. Consequently, there are also two alternative hypotheses for the moderating impact of deal size on the relationship between having an R\&D goal orientation and innovation performance.

Direct effect of deal size on post M\&A innovation performance

H4a: Deal size is positively related to post-acquisition innovation performance.

H4b: Deal size is negatively related to post-acquisition innovation performance.

Moderating effect of deal size on the relationship between $R \& D$ goal orientation and post M\&A innovation performance 
H5a: The size of the deal positively moderates the relationship between $\mathrm{R} \& \mathrm{D}$ goal orientation and post-acquisition innovation performance. That is, the relationship $\mathrm{R} \& \mathrm{D}$ goal orientation and post-acquisition innovation performance is stronger for larger acquisitions (than for smaller acquisitions).

H5b: The size of the deal negatively moderates the relationship between $\mathrm{R} \& \mathrm{D}$ goal orientation and postacquisition innovation performance. That is, the relationship R\&D goal orientation and post-acquisition innovation performance is weaker for larger acquisitions (than for smaller acquisitions).

\section{Methodology}

\subsection{Data sources and description}

We use data from Orbis and Zephyr, the two databases provided by the European private data vendor Bureau van Dijk that collects data on worldwide M\&A deals, initial private offerings, private equity deals, venture capital deals, and rumours thereof. We collect all acquisitions made by pharmaceutical firms between 1 January 2006 and 31 December 2012. These are firms classified under 325412: "Pharmaceutical Preparation Manufacturing" under the NAICS 2012 industry classification.

The period 2006 to 2012 is chosen for two reasons. First, we would like to add to the literature that has predominantly examined this industry using data from the 1980s up to 2003 (Cohen, 2005; Pammolli et al., 2011). While these studies cover the period of the first two merger waves (Grabowski \& Kyle, 2012), there are, to the best of our knowledge, no studies on M\&A activity in this industry after 2003. The second reason is that since Orbis collects data even after this time window, we can examine the post-closure M\&A integration period as well. Evidence suggests that it takes firms between twelve months to two years to have completed integration and the first patents are filed (Grimpe, 2007).

In addition to the data on acquisitions, Orbis is also our source of data on patent applications made by the acquiring firms. We use patent applications according to the following criteria: (1) they were filed between 01/01/2006 and $31 / 12 / 2014$; (2) the current owner includes a firm in the pharmaceutical industry with a NAICS classification of 325412 "Pharmaceutical Preparation Manufacturing"; (3) they were classified under the International Patent Classification (IPC); (4) they were granted. The application date is used rather than the grant date, because the innovation occurs closer to the application date rather than to the grant date; the latter depends on the review process of the patent office (Desyllas \& Hughes, 2010; Hall, 2007).

We then add financial data derived from Orbis, Standard \& Poor's COMPUSTAT database and manual searching of financial reports and press releases. Our final sample consists of 445 acquisitions made by 165 firms, in which 272 deals were domestic and 173 deals were cross-border. To better understand the timing of the variables included, a timeline is included in Figure 1 below in reference to a particular acquisition (termed focal acquisition here). From the focal year, patents are measured up to two years following the acquisition date. Acquisition experience is measured up to three years prior to the acquisition.

\subsection{Variable definitions}

\section{Dependent Variables}

$\operatorname{Ln}(1+$ Patents $)$ is the natural logarithm of $1+$ the count of all patents granted to a firm in the two years after the focal acquisition (1+count is used to allow for the fact in some years, there are no patents filed, and the natural logarithm is used to ameliorate skewness). Ideally, post-acquisition innovation is measured using newly introduced products (Hagedoorn \& Cloodt, 2003; Prabhu et al., 2005). However, the average cycle time of clinical trials is six to eight years (Pammolli et al., 2011), and the total cycle time of both drug discovery and subsequent drug development (including clinical trials) takes 13.5 years on average (Paul et al., 2010). To avoid these large time lags, we chose to use the count of granted patents.

To increase the construct validity of this variable, we also estimated our models using a second dependent variable $\ln (1+A 61 \mathrm{~K}$ Patents $)$. This variable uses granted patents classified in International Patent Classification (IPC) under A61K. Patents classified under IPC as A61K include "Preparations for medical, dental, or toilet purposes". More specifically, A61K includes all 'drug or other biological compositions' that are capable of curing or limiting diseases, influence physiological body functions (for example growth promotors and birth controls), and diagnosing by means of in vivo testing. These patents are therefore strictly related to the development of new pharmaceutical drugs.

\section{Independent variables}

There are three independent variables in this model. The first, $R \& D$ Goal Orientation, is an indicator variable that

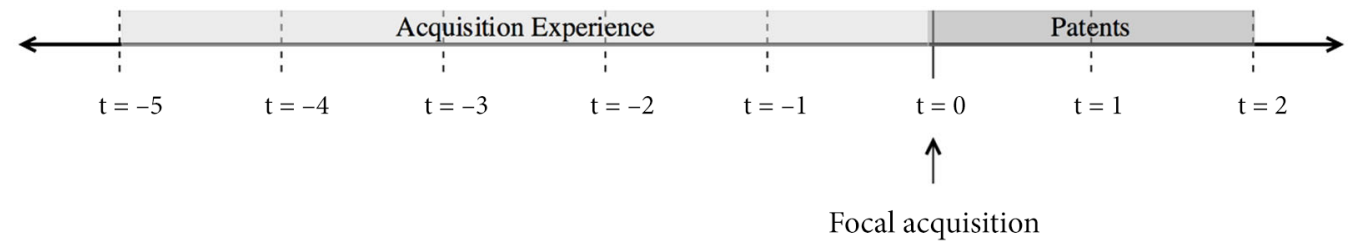

Figure 1. Timeline showing focal acquisition in time 
is 1 if the goal of the acquisition was explicitly for the purpose of R\&D (based on the synopsis of the acquisition deal). Deal synopses are short descriptions of the deal which are collected via press releases, company statements etc. This indicator variable is 0 if no such explicit goal was stated, or if an alternative goal was stated (such as market expansion etc.). The second variable, Acquisition Experience, is measured by the total number of acquisitions (domestic and cross-border) completed by the acquirer in the three years before the focal acquisition. Most studies involving measures of acquisition experience assume a three year window (Dikova \& Rao Sahib, 2013). They reason that in most industries, for example banking, firms make an acquisition and then allow three years for the integration process, before considering a second acquisition. The third is Deal size, measured as the monetary value of the deal reported in billions of US dollars.

\section{Control variables}

To account for other variables that could affect innovation performance, we include the following control variables. First, R\&D intensity of the acquirer is measured by ratio of R\&D expenditure to sales (Ahuja \& Katila, 2001; Higgins \& Rodriguez, 2006; Ornaghi, 2009; Prabhu et al., 2005). This measures the internal investments of the acquirer in $R \& D$ scaled by acquirer size and is a measure of internal $R \& D$ efforts. Second, Relative Size is the ratio between the deal value of the acquisition and the market capitalization of the acquirer. Next, we measure industry similarity between the acquirer and target with two variables: (1) Identical industry, coded 1 whether the acquirer and target operate in the same industry using all six digits of the NAICS Industry Classification, 0 otherwise; (2) Similar industry, defined using the four-digit NAICS code. The latter dummy measures whether the target and acquirer are active is similar, but not identical industries, and is coded 0 when the industries are identical or completely different. Last, we include Cross-border which is 1 if the acquisition is cross-border, and 0 when the acquisition is domestic.

\section{Results}

Table 1 shows the means, standard deviations and correlations for all variables. All correlations are below the standard cut-offs used to detect multi-collinearity. The majority of acquirers have added less than 150 patents in the two years following the acquisition, but there are some acquirers with many patents. There are 91 acquisitions made by 41 firms after which 0 patents were granted.

We interpret the results from our regression models presented in Table 2 with $L n(1+$ Patents $)$ as dependent variable. We use ordinary least squares as our dependent variable is no longer skewed following this logarithmic transformation. We present our results in sequential logic. Model 1 is the model with control variables only. Model 2 adds R\&D goal orientation, Acquisition Experience and Deal size in levels and tests hypotheses 1, 2 and 4 . Model 3 adds the interaction term Acquisition Experience $^{*} R \& D$ goal orientation to Model 2. Similarly, Model 4 adds the interaction term Deal size ${ }^{*} \& \& D$ goal orientation to Model 2. The last column, Model 5 is the saturated model and includes both interaction terms, Acquisition Experience ${ }^{*} \& D$ goal orientation and Deal size ${ }^{*} R \& D$ goal orientation. Across these models, the $\mathrm{R}^{2}$ values indicate that the explanatory power of our models is rather low, but this is often the case panel datasets such as ours. Also, this should not be of great concern as our interest is in explaining the contribution of our independent variables rather than using the model for prediction.

Model 2 of Table 2 yields support for hypotheses 1, 2 and 4 . The coefficients of $R \& D$ goal orientation, Acquisition Experience and Deal size are statistically significant and

Table 1. Descriptive statistics and correlations $(\mathrm{N}=445)$

\begin{tabular}{|l|c|c|c|c|c|c|c|c|c|c|c|}
\hline \multicolumn{1}{|c|}{ Variables } & Mean & $\begin{array}{c}\text { Std. } \\
\text { Dev }\end{array}$ & $(1)$ & $(2)$ & $(3)$ & $(4)$ & $(5)$ & $(6)$ & (7) & (8) & (9) \\
\hline 1. Ln(1+Patents) & 3.03 & 2.45 & 1.00 & & & & & & & & \\
\hline 2. $\ln (1+$ A61K Patents) & 2.52 & 2.33 & $0.94^{*}$ & 1.00 & & & & & & & \\
\hline 3. R\&D Intensity & 0.57 & 2.31 & 0.02 & 0.01 & 1.00 & & & & & & \\
\hline 4. Relative Size & 1.62 & 8.66 & 0.01 & -0.01 & $0.66^{*}$ & 1.00 & & & & & \\
\hline 5. Identical Industry & 0.41 & 0.49 & $-0.10^{*}$ & -0.03 & -0.02 & 0.01 & 1.00 & & & & \\
\hline 6. Similar Industry & 0.07 & 0.25 & 0.03 & -0.03 & 0.08 & 0.02 & $-0.23^{*}$ & 1.00 & & & \\
\hline 7. Cross-Border & 0.39 & 0.49 & 0.06 & 0.09 & -0.02 & -0.02 & 0.02 & 0.02 & 1.00 & & \\
\hline $\begin{array}{l}\text { 8. R\&D Goal } \\
\text { Orientation }\end{array}$ & 0.49 & 0.50 & $0.26^{*}$ & $0.31^{*}$ & -0.02 & -0.04 & $-0.25^{*}$ & 0.00 & 0.07 & 1.00 & \\
\hline $\begin{array}{l}\text { 9. Acquisition } \\
\text { Experience }\end{array}$ & 1.57 & 2.02 & $0.13^{*}$ & 0.07 & -0.07 & -0.06 & -0.05 & 0.01 & $0.23^{*}$ & -0.01 & 1.00 \\
\hline $\begin{array}{l}\text { 10. Deal Size (in USD } \\
\text { billions) }\end{array}$ & 1.15 & 4.68 & $0.19^{*}$ & $0.19^{*}$ & 0.06 & 0.11 & 0.01 & -0.00 & 0.01 & 0.12 & 0.13 \\
\hline
\end{tabular}

* Correlations significant at $5 \%$ level. 
Table 2. Least squares regression models with $\operatorname{Ln}(1+$ Patents $)$ as dependent variable

\begin{tabular}{|c|c|c|c|c|c|}
\hline & Model 1 & Model 2 & Model 3 & Model 4 & Model 5 \\
\hline \multirow{2}{*}{ R\&D Intensity } & -0.006 & -0.012 & -0.012 & -0.020 & -0.019 \\
\hline & $(0.068)$ & $(0.071)$ & $(0.071)$ & $(0.070)$ & $(0.070)$ \\
\hline \multirow{2}{*}{ Relative Size } & 0.006 & 0.005 & 0.004 & -0.002 & -0.002 \\
\hline & $(0.019)$ & $(0.019)$ & $(0.019)$ & $(0.019)$ & $(0.019)$ \\
\hline \multirow{2}{*}{ Identical industry } & $-0.525^{\star \star}$ & -0.101 & -0.121 & -0.089 & -0.103 \\
\hline & $(0.258)$ & $(0.303)$ & $(0.304)$ & $(0.301)$ & $(0.302)$ \\
\hline \multirow{2}{*}{ Similar industry } & -0.049 & -0.964 & -0.962 & -0.879 & -0.881 \\
\hline & $(0.496)$ & $(0.604)$ & $(0.604)$ & $(0.600)$ & $(0.601)$ \\
\hline \multirow{2}{*}{ Crossborder dummy } & 0.301 & -0.081 & -0.082 & -0.084 & -0.084 \\
\hline & $(0.254)$ & $(0.294)$ & $(0.294)$ & $(0.292)$ & $(0.292)$ \\
\hline \multirow{2}{*}{ R\&D Goal Orientation } & & $1.109^{* * *}$ & $1.312^{* * *}$ & $1.275^{* * *}$ & $1.408^{* * *}$ \\
\hline & & $(0.289)$ & $(0.355)$ & $(0.295)$ & $(0.355)$ \\
\hline \multirow{2}{*}{ Acquisition experience } & & $0.183^{* * *}$ & $0.237^{* * *}$ & $0.168^{* *}$ & $0.205^{\star *}$ \\
\hline & & $(0.069)$ & $(0.088)$ & $(0.069)$ & $(0.088)$ \\
\hline \multirow{2}{*}{ Deal Size } & & $0.070^{* * *}$ & $0.073^{* * *}$ & $0.218^{* * *}$ & $0.214^{* * *}$ \\
\hline & & $(0.026)$ & $(0.026)$ & $(0.068)$ & $(0.068)$ \\
\hline Acquisition experience ${ }^{*} \mathrm{R} \& D$ Goal Orientation & & & $\begin{array}{l}-0.134 \\
(0.136)\end{array}$ & & $\begin{array}{c}-0.092 \\
(0.137)\end{array}$ \\
\hline Deal Size * R\&D Goal Orientation & & & & $\begin{array}{c}-0.173^{* *} \\
(0.073)\end{array}$ & $\begin{array}{c}-0.166^{* *} \\
(0.074)\end{array}$ \\
\hline \multirow{2}{*}{ Constant } & $3.150^{* * *}$ & $2.443^{* * *}$ & $2.361^{* * *}$ & $2.362^{* * *}$ & $2.309^{* * *}$ \\
\hline & $(0.192)$ & $(0.285)$ & $(0.297)$ & $(0.285)$ & $(0.296)$ \\
\hline Observations & 445 & 445 & 445 & 445 & 445 \\
\hline R-squared & 0.014 & 0.117 & 0.120 & 0.134 & 0.135 \\
\hline
\end{tabular}

Standard errors in parentheses, ${ }^{\star *} \mathrm{p}<0.01,{ }^{\star \star} \mathrm{p}<0.05,{ }^{\star} \mathrm{p}<0.1$.

positive ( $\mathrm{p}<0.01)$. Model 3 shows that there is insufficient evidence to indicate that Acquisition Experience moderates the effect of $R \& D$ goal orientation on post-acquisition innovative performance. The interaction term Acquisition Experience $^{*} R \& D$ goal orientation is statistically insignificant. However, from Model 4, we do find evidence that Deal size negatively moderates the effect of $R \& D$ goal orientation on post-acquisition innovation and this effect is statistically significant $(\mathrm{p}<0.01)$. This suggests that although large deals with an R\&D goal orientation foster post-acquisition innovation, their effect has diminishing returns. That is, the positive effect of $R \& D$ goal orientation on post-acquisition innovation eventually wanes. This suggests that large deals even if they are R\&D goal oriented may become too large and cumbersome to manage, and that the benefits they deliver in terms of post-acquisition innovation could be limited. Model 5 that presents the saturated model, reaffirms the findings from the previous columns. In terms of the control variables, while Identical is statistically significant and negative in the controls only model in Column 1, it is no longer statistically significant in the remainder of the models. The other control variables are statistically insignificant in the other specifications of the model (for brevity, year dummies are not reported as they were all statistically insignificant).
In analyses not reported here, we estimated this model when the dependent variable had been restricted to include only drug patents classified as A61K. These results were largely similar to those in Table 2 except that we did not find support for the Hypothesis found Acquisition Experience was no longer statistically significant. This seems to suggest that for very specific types of M\&As such as those involving drug patents, that the Acquisition Experience of the acquirer is secondary. Also, the Cross Border dummy which was statistically insignificant in the model with all patents was marginally significant and positive in the estimations on the sample with drug patents only yielding some evidence that international mergers may foster greater innovation for this narrow category of acquisitions.

\section{Discussion and conclusions}

In this hyper competitive world, pharmaceutical firms are faced with challenges of developing and acquiring new blockbuster drugs, renewing expiring patents of the current ones, and managing the ballooning costs of these innovation activities which often run in billions of dollars (Khanna, 2012; Malik, 2009). With an increased importance of innovation performance in the pharmaceutical 
industry, firms often engage in a number of innovation strategies that include in-house R\&D efforts, joint R\&D efforts with other firms, and acquiring innovation by engaging in mergers and acquisitions (Ahuja \& Katila, 2001; Chaudhuri \& Tabrizi, 1999). Despite the importance and many benefits of M\&As, prior research investigating the relationship between M\&As and firm's innovation performance has been plagued with inconclusive findings (Cassiman et al., 2005; Comanor \& Scherer, 2013; Ornaghi, 2009).

We extend the research on M\&As and firm innovation by examining a) the acquirer's motive of the acquisition and its role in firm's post-acquisition innovation performance, b) how acquirer's acquisition experience and, c) deal size impact the innovation performance relationship. To do so, we examine the M\&A activity of pharmaceutical industry from 2006 to 2012. Our findings support our theorizing and suggest that having an explicit R\&D goal helps a firm to boost its post-acquisition innovation performance. Further, our results indicate that acquirer's prior acquisition experience enables the firm to develop better target selection and integration capabilities, hence, helps boost its post-acquisition innovation performance. Additionally, we found that larger deals help firms to elevate their innovation performance as the firms acquire more resources and capabilities than they would have by making smaller acquisitions. However, this effect of deal size has diminishing returns, meaning that even if the deal is $\mathrm{R} \& \mathrm{D}$-oriented, the positive effect of $\mathrm{R} \& \mathrm{D}$ orientation on post-merger innovation performance decreases in larger deals. Below we discuss the contributions and implications of these findings.

First, we offer more insights to innovation literature by further exploring how firms can use M\&As as an effective strategy to boost their innovation performance. Prior research has found mixed results between M\&As and firm's innovation performance (Cassiman et al., 2005; Comanor \& Scherer, 2013; Ornaghi, 2009, Zhao et al., 2019). Our findings indicate that the inconclusive findings can be explained by examining the firm's motives in technology acquisitions. Applying theoretical arguments from psychology literature, including motivational theory (Dweck, 1986), attention-based view (Ocasio, 1997; Yu et al., 2005) and the goal-orientation theory (Button et al., 1996), our study explains how having an explicit R\&D goal right from the begining of an M\&A process can help firms boost their innovation after the acquisition or merger. We suggest that having an explicit R\&D learning goal orientation will guide firms and their employees to focus on technology-related tasks during target selection as well as the knowledge integration part of post-acquisition process, which can help to enhance firms' innovation performance. We hope that further research can build on our understanding on the role of motivation in the innovation process. Moreover, we also expect that this study will encourage scholars to apply and link theories from different fields to explain strategic management issues.
Second, our study once again emphasizes the important roles of M\&A experience and deal size on determining M\&A post-integration performance (Lee et al., 2019). Studies that apply the resource-based view theory have investigated the impact of these two variables on M\&A innovation performance (Ahuja \& Katila, 2001; Ringel \& Choy, 2017). Our research not only confirms findings from these papers but also suggests that acquiring larger firms with an explicit R\&D motive can be detrimental for the firm's post-acquisition innovation performance. During integration, the acquirer has to focus on not only acquiring resources but also maintaining and retaining the valuable employees and capabilities in both the firms which can be quite challenging in larger acquisitions ( $\mathrm{Pa}-$ ruchuri et al., 2006; Puranam et al., 2006; Puranam \& Srikanth, 2007).

From a practitioner standpoint, our findings suggest that firms need to be explicit in their motives for acquisitions. Such motives not only communicate the intentions to the external stakeholders but they also help communicate the strategy to the firm's own and target's employees. Research suggests that communication is a critical component of successful innovation programs (Cohen \& Levinthal, 1990). Communicating the intent of acquisition can signal to employees of both firms on what the firm considers important. This can motivate them to have a learning goal orientation as they are motivated to participate in processes of sharing their knowledge, learning and creating new knowledge. In addition, managers should carefully consider the amount of resources to acquire. Although larger targets can offer more valuable resources and capabilities which help to enhance the innovation performance of the firm after integration, too large targets can be troublesome and hard to be "absorbed". In addition to the size of the target, the acquiring firm may also take into account the $\mathrm{R} \& \mathrm{D}$ expenditure of the other firm, in order to achieve the greatest exploitation of technological knowledge, as suggested by Song and Leker (2018).

\section{Limitations and future research}

As with all studies, we acknowledge that our current study suffers from limitations. However, these limitations can serve as opportunities for future research. First, we conducted this study in the context of pharmaceutical industry. Future research could build on our work by examining these relationships in different technological industries. While we expect our findings to hold in similar situations, we anticipate that these results might be different in another industry. For example, computer or mobile industries do not have as long development time as pharmaceutical industry has but are more fast paced and competitive than pharmaceutical industry. Such industry specific factors could amplify the relationships observed in our study. Thus, there are many opportunities to extend our research to different settings.

Second, while our research provides a starting point for investigation of acquirer's explicit R\&D goal orientation, 
there are many other factors that influence the motivation of R\&D employees. For example, there are a lot of team level and individual level factors that can influence $R \& D$ goal orientation of the employees (Alexander \& van Knippenberg, 2014). Therefore, future studies could look into the team dynamics of the innovation process to better understand how a firm's explicit R\&D goal orientation trickles down at the team and individual level to influence innovation performance.

Finally, pharmaceutical firms invest billions of dollars in innovation activities in hope that some of these activities would produce a blockbuster drug in the future that will boost the firm's stock and accounting performance. Due to the long development time in the industry, we are unable to examine the financial impact of a firm's innovation performance. Therefore, future researchers can examine whether M\&As initiated with an explicit R\&D goal orientation are helpful for firm's financial performance.

\section{References}

Agarwal, R., \& Helfat, C. E. (2009). Strategic renewal of organizations. Organization Science, 20(2), 281-293. https://doi.org/10.1287/orsc.1090.0423

Ahuja, G., \& Katila, R. (2001). Technological acquisitions and the innovation performance of acquiring firms: a longitudinal study. Strategic Management Journal, 22(3), 197-220. https://doi.org/10.1002/smj.157

Alexander, L., \& Knippenberg, D. V. (2014). Teams in pursuit of radical innovation: A goal orientation perspective. Academy of Management Review, 39(4), 423-438. https://doi.org/10.5465/amr.2012.0044

Baum, J. A. C., Li, X. S., \& Usher, J. M. (2000). Making the next move: How experiential and vicarious learning shape the location of chains' acquisitions. Administrative Science Quarterly, 45(4), 766-801. https://doi.org/10.2307/2667019

Birkinshaw, J., Bresman, H, \& Hakanson, L. (2000). Managing the post-acquisition integration process: How the human integration and task integration processes interact to foster value creation. Journal of Management Studies, 37(3), 395-425. https://doi.org/10.1111/1467-6486.00186

Bobko, P., \& Colella, A. (1994). Employee reactions to performance standards: A review and research propositions. Personnel Psychology, 47, 1-29.

https://doi.org/10.1111/j.1744-6570.1994.tb02407.x

Button, S. B., Mathieu, J. E., \& Zajac, D. M. (1996). Goal orientation in organizational research: A conceptual and empirical foundation. Organizational Behavior and Human Decision Processes, 67(1), 26-48.

https://doi.org/10.1006/obhd.1996.0063

Bower, J. L. (2001). Not M\&As are alike: And that matters. In Mergers \& Acquisitions: A Critical Reader. Routledge.

Capron, L., \& Pistre, N. (2002). When do acquirers earn abnormal returns? Strategic Management Journal, 23(9), 781-794. https://doi.org/10.1002/smj.262

Cassiman, B., Colombo, M. G., Garrone, P., \& Veugelers, R. (2005). The impact of M\&A on the R\&D process: An empirical analysis of the role of technological- and market-relatedness. Research Policy, 34(2), 195-220.

https://doi.org/10.1016/j.respol.2005.01.002
Chakrabarti, A., \& Mitchell, W. (2013). The persistent effect of geographic distance in acquisition target selection. Organization Science, 24(6), 1805-1826.

https://doi.org/10.1287/orsc.1120.0811

Chaudhuri, S., \& Tabrizi, B. (1999). Capturing the real value in high-tech acquisitions. Havard Business Review, 77(5), 123-130, 185. https://hbr.org/1999/09/capturing-the-realvalue-in-high-tech-acquisitions

Cohen, F. J. (2005). Macro trends in pharmaceutical innovation. Nature Reviews Drug Discovery, 4, 78-84.

https://doi.org/10.1038/nrd1610

Cohen, W. M., \& Levinthal, D. A. (1990). Absorptive capacity: A new perspective on learning and innovation. Administrative Science Quarterly, 35(1), 128-152. https://doi.org/10.2307/2393553

Cloodt, M., Hagedoorn, J., \& Kranenburg, H. V. (2006). Mergers and acquisitions: their effect on the innovative performance of companies in high-tech industries. Research Policy, 35(5), 642-654. https://doi.org/10.1016/j.respol.2006.02.007

Comanor, W. S., \& Scherer, F. M. (2013). Mergers and innovation in the pharmaceutical industry. Journal of Health Economics, 32(1), 106-113. https://doi.org/10.1016/j.jhealeco.2012.09.006

Desyllas, P., \& Hughes, A. (2010). Do high technology acquirers become more innovative? Research Policy, 39(8), 1105-1121. https://doi.org/10.1016/j.respol.2010.05.005

Diener, C. I., \& Dweck, C. S. (1978). An analysis of learned helplessness: Continuous changes in performance, strategy, and achievement cognitions following failure. Journal of Personality and Social Psychology, 36, 451-462. https://doi.org/10.1037/0022-3514.36.5.451

Dikova, D., \& Rao Sahib, P. (2013). Is cultural distance a bane or a boon for cross-border acquisition performance? Journal of World Business, 48(1), 77-86. https://doi.org/10.1016/j.jwb.2012.06.009

Dweck, C. S. (1986). Motivational processes affecting learning. American Psychologist, 41(10), 1040-1048. https://doi.org/10.1037/0003-066X.41.10.1040

Eisenhardt, K. M., \& Martin, J. A. (2000). Dynamic capabilities: What are they? Strategic Management Journal, 21(10/11), 1105-1121. https://doi.org/10.1002/10970266(200010/11)21:10/11<1105::AID-SMJ133>3.0.CO;2-E

Farr, J. L., Hofmann, D. A., \& Ringenbach, K. L. (1993). Goal orientation and action control theory: Implications for industrial and organizational psychology. International Review of Industrial and Organizational Psychology, 8, 193-232.

Fernald, K. D. S., Pennings, H. P. G., van den Bosch, J. F., Commandeur, H. R., \& Classen, E. (2017). The moderating role of absorptive capacity and the differential effects of acquisitions and alliances on Big Pharma firms' innovation performance. PloS ONE, 12(2), e0172488.

https://doi.org/10.1371/journal.pone.0172488

Graebner, M. E. (2004). Momentum and serendipity: How acquired leaders create value in the integration of technology firms. Strategic Management Journal, 25(8/9), 751-777. https://doi.org/10.1002/smj.419

Grabowski, H. G., \& Kyle, M. (2012). Mergers, acquisitions, and alliances. In P. M. Danzon \& S. Nicholson (Eds.), The Oxford handbook of the economics of the biopharmaceutical industry. Oxford University Press.

https://doi.org/10.1093/oxfordhb/9780199742998.013.0018

Graebner, M. E., Eisenhardt, K. M., \& Roundy, P. T. (2010). Success and failure in technology acquisitions: Lessons for buyers and sellers. Academy of Management Perspectives, 24(3), 73-92. https://doi.org/10.5465/amp.24.3.73 
Grimpe, C. (2007). Successful product development after firm acquisitions: The role of research and development. The Journal of Product Innovation Management, 24(6), 614-628.

https://doi.org/10.1111/j.1540-5885.2007.00275.x

Hagedoorn, J., \& Cloodt, M. (2003). Measuring innovative performance: Is there an advantage in using multiple indicators? Research Policy, 32(8), 1365-1379.

https://doi.org/10.1016/S0048-7333(02)00137-3

Hagedoorn, J., \& Sadowski, B. (1999). The transition from strategic technology alliances to mergers and acquisitions: An exploratory study. Journal of Management Studies, 36(1), 87-107. https://doi.org/10.1111/1467-6486.00127

Hakanson, L. (1995). Learning through acquisitions: Management and integration of foreign R\&D laboratories. International Studies of Management and Organization, 25(1-2), 121-157. https://doi.org/10.1080/00208825.1995.11656654

Hall, B. H. (2007). Patents and patent policy. Oxford Review of Economic Policy, 23(4), 568-587. https://doi.org/10.1093/oxrep/grm037

Hamel, G. (2000). Waking up IBM: how a gang of unlikely rebels transformed Big Blue. Harvard Business Review, 78(4), 137146. https://hbr.org/2000/07/waking-up-ibm-how-a-gang-ofunlikely-rebels-transformed-big-blue

Han, J., Jo, G. S., \& Kang, J. (2018). Is high-quality knowledge always beneficial? Knowledge overlap and innovation performance in technological mergers and acquisitions. Journal of Management \& Organization, 24(2), 258-278.

https://doi.org/10.1017/jmo.2016.35

Haspeslagh, P. C., \& Jemison, D. B. (1991). Managing acquisitions. The Free Press.

Hayward, M. L. A. (2002). When do firms learn from their acquisition experience? Evidence from 1990 to 1995. Strategic Management Journal, 23(1), 21-39.

https://doi.org/10.1002/smj.207

Higgins, M. J., \& Rodriguez, D. (2006). The outsourcing of R\&D through acquisitions in the pharmaceutical industry. Journal of Financial Economics, 80(2), 351-383.

https://doi.org/10.1016/j.jfineco.2005.04.004

Hitt, M. A., Harrison, J. S., \& Ireland, R. D. (2001). Mergers \& acquisitions: A guide to creating value for stakeholders. Oxford University Press.

Hitt, M. A., Hoskisson, R. E., Johnson, R. A., \& Moesel, D. D. (1996). The market for corporate control and firm innovation. Academy of Management Journal, 39(5), 1084 -1119. https://doi.org/10.5465/256993

Jeon, J., Hong, S., Ohm, J., \& Yang, T. (2015). Causal relationships among technology acquisition, absorptive capacity, and innovation performance: evidence from the pharmaceutical industry. Plos One, 10(7), e0131642.

https://doi.org/10.1371/journal.pone.0131642

Jo, G. S., Park, G., \& Kang, J. (2016). Unravelling the link between technological M\&A and innovation performance using the concept of relative absorptive capacity. Asian Journal of Technology Innovation, 24(1), 1-22. https://doi.org/10.1080/19761597.2015.1128340

Kaul, A., \& Wu, B. (2015). A capabilities-based perspective on target selection in acquisitions. Strategic Management Journal, 37(7), 1220-1239. https://doi.org/10.1002/smj.2389

Khanna, I. (2012). Drug discovery in pharmaceutical industry: Productivity challenges and trends. Drug Discovery Today, 17(19-20), 1088-1102.

https://doi.org/10.1016/j.drudis.2012.05.007
Kim, J. Y., \& Finkelstein, S. (2009). The effects of strategic and market complementarity on acquisition performance: Evidence from the US commercial banking industry, 1989-2001. Strategic Management Journal, 30(6), 617-0646.

https://doi.org/10.1002/smj.754

Laamanen, T., \& Keil, T. (2008). Performance of serial acquirers: toward an acquisition program perspective. Strategic Management Journal, 29(6), 633-672. https://doi.org/10.1002/smj.670

Lange, S., \& Wagner, M. (2019). The influence of exploratory versus exploitative acquisitions on innovation output in the biotechnology industry. Small Business Economics. https://doi.org/10.1007/s11187-019-00194-1

Larsson, R., \& Finkelstein, S. (1999). Integrating strategic, organizational, and human resource perspectives on mergers and acquisitions: A case survey of synergy realization. Organization Science, 10(1), 1-26. https://doi.org/10.1287/orsc.10.1.1

Lee, Y. J., Shin, K., \& Kim, E. (2019). The influence of a firm's capability and dyadic relationship of the knowledge base on ambidextrous innovation in biopharmaceutical M\&As. Sustanability, 11(18), 4920. https://doi.org/10.3390/su11184920

Makri, M., Hitt, M. A., \& Lane, P. J. (2010). Complementary technologies, knowledge relatedness and invention outcomes in high technology mergers and acquisitions. Strategic Management Journal, 31(6), 602-628. https://doi.org/10.1002/smj.829

Malik, N. N. (2009). Biotech acquisitions by big pharma: why and what is next. Drug Discovery Today, 14(17-18), 818-821. https://doi.org/10.1016/j.drudis.2009.06.012

Ocasio, W. (1997). Towards an attention-based view of the firm. Strategic Management Journal, 18, 187-206.

https://doi.org/10.1002/(SICI)1097-0266(199707)18:1+ $<187::$ AID-SMJ936>3.3.CO;2-B

Ornaghi, C. (2009). Mergers and innovation in big pharma. International Journal of Industrial Organization, 27(1), 70-79. https://doi.org/10.1016/j.ijindorg.2008.04.003

Pammolli, F., Magazzini, L., \& Riccaboni, M. (2011). The productivity crisis in pharmaceutical R\&D. Nature Reviews. Drug Discovery, 10(6), 428-438. https://doi.org/10.1038/nrd3405

Paruchuri, S., Nerkar, A., \& Hambrick, D. C. (2006). Acquisition integration and productivity losses in the technical core: Disruption of inventors in acquired companies. Organization Science, 17(5), 545-562. https://doi.org/10.1287/orsc.1060.0207

Paul, S. M., Mytelka, D. S., Dunwiddie, C. T., Persinger, C. C., Munos, B. H., Lindborg, S. R., \& Schacht, A. L. (2010). How to improve $\mathrm{R} \& \mathrm{D}$ productivity: the pharmaceutical industry's grand challenge. Nature Reviews. Drug Discovery, 9(3), 203214. https://doi.org/10.1038/nrd3078

Penner-Hahn, J., \& Shaver, J. M. (2005). Does international research and development increase patent output? An analysis of Japanese pharmaceutical firms. Strategic Management Journal, 26(2), 121-140. https://doi.org/10.1002/smj.436

Prabhu, J. C., Chandy, R. K., \& Ellis, M. E. (2005). The impact of acquisitions on innovation: Poison pill, Placebo, or Tonic? Journal of Marketing, 69, 114-130. https://doi.org/10.1509/jmkg.69.1.114.55514

Prahalad, C. K., \& Bettis, R. A. (1986). The dominant logic: a new linkage between diversity and performance. Strategic Management Journal, 7(6), 485-501. https://doi.org/10.1002/smj.4250070602

Puranam, P., Powell, B. C., \& Singh, H. (2006). Due diligence failure as a signal detection problem. Strategic Organization, 4(4), 319-348. https://doi.org/10.1177/1476127006069426 
Puranam, P., \& Srikanth, K. (2007). What they know vs. what they do: How acquirers leverage technology acquisitions. Strategic Management Journal, 28(8), 805-825. https://doi.org/10.1002/smj.608

Ranft, A. L., \& Lord, M. D. (2000). Acquiring new knowledge: The role of retaining human capital in acquisitions of hightech firms. The Journal of High Technology Management Research, 11(2), 295-319. https://doi.org/10.1016/S1047-8310(00)00034-1

Ravenscraft, D. J., \& Scherer, F. M. (1987). Life after takeover. The Journal of Industrial Economics, 36(2), 147-156. https:// doi.org/10.2307/2098409

Ringel, M. S., \& Choy, M. K. (2017). Do large mergers increase or decrease the productivity of pharmaceutical R\&D? Drug Discovery Today, 22(12), 1749-1753. https://doi.org/10.1016/j.drudis.2017.06.002

Ruckman, K. (2009). Technology sourcing acquisitions: What they mean for innovation potential. Journal of Strategy and Management, 2(1), 56-75. https://doi.org/10.1108/17554250910948703

Santos, F., \& Eisenhardt, K. M. (2009). Constructing markets and shaping boundaries: Entrepreneurial power in nascent fields. Academy of Management Journal, 52(4), 643-671. https://doi.org/10.5465/amj.2009.43669892

Schildt, H. A., \& Laamanen, T. (2006). Who buys whom: Information environments and organizational boundary spanning through acquisitions. Strategic Organization, 4(2), 111-113. https://doi.org/10.1177/1476127006064065

Schweizer, L. (2005). Knowledge transfer and R\&D in pharmaceutical companies: A case study. Journal of Engineering and Technology Management, 22(4), 315-331. https://doi.org/10.1016/j.jengtecman.2005.09.004

Shelton, L. M. (1988). Strategic business fits and corporate acquisition: Empirical evidence. Strategic Management Journal, 9(3), 279-287. https://doi.org/10.1002/smj.4250090307
Shibayama, S., Tanikawa, K., Fujimoto, R., \& Kimura, H. (2008). Effect of mergers and acquisitions on drug discovery: perspective from a case study of a Japanese pharmaceutical company. Drug Discovery Today, 13(1-2), 86-93. https://doi.org/10.1016/j.drudis.2007.10.015

Shrivastava, P. (1986). Post-merger integration. Journal of Business Strategy, 7(1), 65-76. https://doi.org/10.1108/eb039143

Song, C. H., \& Leker, J. (2018). Differentiation of innovation strategies based on pharmaceutical licensing agreements: Insight from Korean pharmaceutical firms. Technology Analysis \& Strategic Management, 31(2), 169-185. https://doi.org/10.1080/09537325.2018.1490711

Trautwein, F. (1990). Merger motives and merger prescriptions. Strategic Management Journal, 11(4), 283-295. https://doi.org/10.1002/smj.4250110404

Vaara, E., Sarala, R., Stahl, G. K., \& Björkman, I. (2012). The impact of organizational and national cultural differences on social conflict and knowledge transfer in international acquisitions. Journal of Management Studies, 49(1), 1-27. https://doi.org/10.1111/j.1467-6486.2010.00975.x

VandeWalle, D., Cron, W. L., \& Slocum, J. W. Jr. (2001). The role of goal orientation following performance feedback. Journal of Applied Psychology, 86(4), 629-640. https://doi.org/10.1037/0021-9010.86.4.629

Yu, J., Engleman, R. M., \& Van de Ven, A. H. (2005). The integration journey: An attention-based view of the merger and acquisition integration process. Organization Studies, 26(10), 1501-1528. https://doi.org/10.1177/0170840605057071

Zhao, X., Lin, D., \& Hao, T. (2019). A new discussion on the relationship between $M \& A$ and innovation in an emerging market: the moderating effect of post-acquisitions R\&D investment. Technology Analysis \& Strategic Management, 31(12), 1447-1461. https://doi.org/10.1080/09537325.2019.1627310 